\title{
ANTICORPOS SÉRICOS NA DOENÇA CELÍACA
}

\author{
Ceres Concilio ROMALDINI e Dorina BARBIERI ${ }^{* *}$
}

RESUMO - O diagnóstico acurado da doença celíaca é muito importante porque os pacientes devem aderir a uma dieta sem glúten por toda a vida e diante do maior risco de complicações, como as neoplasias intestinais, que poderá advir do não cumprimento rigoroso da dieta. Nesta revisão são apresentados os novos conceitos referentes às formas de apresentação da doença (ativa, silenciosa, latente e potencial) e sua associação com outras enfermidades e são focalizados principalmente o valor e a eficácia da determinação dos anticorpos séricos antigliadina e dos autoanticorpos anti-reticulina, antiendomísio e antitransglutaminase tecidual, no auxílio ao diagnóstico e seguimento da doença celíaca.

DESCRITORES - Doença celíaca. Marcadores sorológicos. Anticorpos séricos. Gliadina. Reticulina. Endomísio. Transglutaminase tecidual.

O diagnóstico acurado da doença celíaca é muito importante embora, muitas vezes, desafiador. Ele é importante porque a dieta sem glúten deve ser seguida por toda a vida e também diante das complicações graves que poderão advir, em conseqüência do não cumprimento rigoroso do tratamento. Vários trabalhos demonstram que a dietoterapia, sem interrupções, assegurará às crianças um crescimento adequado ${ }^{(5)}$. Por outro lado, constata-se entre os celíacos negligentes uma maior freqüência de neoplasias intestinais em relação à população geral ${ }^{(20,26)}$. O diagnóstico acurado é desafiador principalmente pela grande variabilidade da expressão clínica da doença e, deste modo, isoladamente nenhum dos sintomas e sinais desta condição patológica são indicadores absolutos para o seu diagnóstico.

Considerando o espectro de sinais e sintomas, observase em uma das extremidades, aqueles indivíduos com a forma ativa da doença, nos quais é evidente a má absorção, deficiências nutricionais e mesmo manifestações clínicas atípicas. Na outra extremidade do espectro, estão os pacientes assintomáticos, portadores de doença celíaca silenciosa, detectados através de programas de triagem para a doença celíaca. Tanto na forma ativa, como na silenciosa encontra-se uma enteropatia severa.

Em 1993, FERGUSON et al. ${ }^{(17)}$, levando em consideração os diferentes padrões histológicos e dinamicamente inter-relacionados presentes na doença celíaca ${ }^{(28)}$, acrescentam além das formas ativa e silenciosa, as formas latente e potencial da doença. Sob o ponto de vista conceptual, as definições destas formas são ainda pouco claras e na prática são de difícil aplicação, pois algumas vezes a caracterização das mesmas só pode ser feita a posteriori. A forma latente ocorre em duas situações: 1) aquela apresentada pelo paciente celíaco diagnosticado por mucosa plana, que se recuperou com dieta sem glúten, e que na vigência de retorno de dieta com glúten persiste apresentando mucosa normal; 2) aquela em que o paciente, por fatores circunstanciais, foi submetido a biopsia

Mestre em Gastroenterologia pelo Instituto Brasileiro de Estudos e Pesquisas de Gastroenterologia - IBEPEGE. Médica da Unidade de Nutrição e Metabologia do Instituto da Criança "Prof. Pedro de Alcantara" do Hospital das Clínicas da Faculdade de Medicina da Universidade de São Paulo.

* Livre-Docente do Departamento de Pediatria da Faculdade de Medicina da Universidade de São Paulo.

Endereço para correspondência: Dra. Ceres Concilio Romaldini - Unidade de Nutrição e Metabologia - Instituto da Criança do HC da FMUSP - Av. Dr. Enéas Carvalho Aguiar, 647 - 05403-900 São Paulo, SP. 
jejunal, que se mostrou histologicamente normal, e que posteriormente uma nova biopsia revelou mucosa de padrão celíaco. Esta última situação corresponderia de fato a um período pré-instalação da doença celíaca. A forma potencial da doença celíaca é um termo proposto para designar aqueles indivíduos que nunca tiveram um padrão de mucosa plana, mas apresentam algumas alterações histoimunológicas semelhantes às encontradas nos pacientes celíacos. Estas alterações incluem um aumento da densidade de linfócitos intra-epiteliais, particularmente aqueles expressando receptores $\gamma \delta$ e aumento dos anticorpos antigliadina da classe $\operatorname{IgA}$ e $\operatorname{IgM}$ no lavado intestinal. Os parentes de celíacos e aqueles indivíduos com deficiência de IgA, que apresentam estas alterações, seriam considerados portadores da forma potencial da doença celíaca segundo FERGUSON et al. (17).

Por outro lado, está bem documentada a associação da doença celíaca com outras enfermidades, como a dermatite herpetiforme $^{(32)}$ e a deficiência seletiva de $\operatorname{IgA}{ }^{(11)}$. A maioria dos pacientes com dermatite herpetiforme apresentam alterações da mucosa intestinal histologicamente semelhantes àquelas encontradas na doença celíaca, embora estes pacientes sejam freqüentemente assintomáticos do ponto de vista digestivo ${ }^{(28)}$. A deficiência seletiva de imunoglobulina A é a condição mais freqüente associada à doença celíaca na infância, podendo ocorrer 10 vezes mais nos celíacos do que na população geral ${ }^{(11)}$. Outras doenças, a maioria com patogênese auto-imune, são observadas com uma freqüência maior do que a esperada nos pacientes celíacos; entre estas estão incluídas o diabetes mellitus tipo 1 e as doenças auto-imunes da tiróide $^{(4,14)}$. A associação da doença celíaca com enfermidades genéticas como, por exemplo, a síndrome de Down também tem sido relatada ${ }^{(53)}$.

Nos últimos anos, vários estudos imunológicos vêm sendo realizados não só em consideração à patogênese da lesão celíaca, mas também tem havido grande interesse e uma busca contínua de um teste soroimunológico simples, de alta sensibilidade e custo efetivo para a triagem da doença celíaca.

O desenvolvimento de técnicas laboratoriais, a produção de anticorpos monoclonais e a purificação de antígenos, possibilitaram a introdução de vários métodos sorológicos nãoinvasivos para se detectar os anticorpos antigliadina, anti-reticulina, antiendomísio e, mais recentemente, os anticorpos antitransglutaminase tecidual. Estes anticorpos presentes na doença celíaca são principalmente da classe IgA. Na prática, portanto, é necessária a dosagem da IgA sérica previamente à dosagem dos anticorpos. Deste modo, naqueles indivíduos com ausência de IgA recomendase a dosagem do anticorpo da classe IgG.

Diante da grande variabilidade das formas de apresentação da doença celíaca e da sua associação com outras enfermidades, os testes sorológicos tornaram-se importantes marcadores da doença e imprescindíveis antes da realização obrigatória da biopsia intestinal para firmar o seu diagnóstico.

Atualmente, a determinação sérica principalmente dos anticorpos antigliadina e antiendomísio, é largamente usada para o rastreamento da doença celíaca, assim como no seguimento dos pacientes em relação à aderência ao tratamento.

\section{ANTICORPOS ANTIGLIADINA}

Os anticorpos circulantes antigliadina (AAG) foram inicialmente identificados em trabalhos especulativos ${ }^{(6,44)}$ e seu uso rotineiro laboratorial, para auxílio no diagnóstico da doença celíaca, só ocorreu após as décadas de 70 e 80 com o desenvolvimento dos métodos para a detecção de anticorpos, como a imunofluorescência, radioimunoensaio e os ensaios imunoenzimáticos. A partir desta data, existem inúmeros relatos do comportamento destes anticorpos na doença celíaca, avaliados pelas diferentes técnicas, assim como da diversidade de resultados em relação à sensibilidade e especificidade destes ensaios ${ }^{(3}$ $8,10,18,29,33,36,37,39,49,50,51)$.

Os AAG são predominantemente das classes IgA e IgG e detectados no soro da maioria dos celíacos não tratados e também naqueles assintomáticos. Após a introdução da dieta isenta de glúten observa-se um declínio gradual de seus níveis séricos ${ }^{(10,39}$, ${ }^{42)}$. Estudos mostram uma queda dos títulos dos anticorpos IgA após três meses de restrição de glúten, queda esta que se mantém, até que, com um ano de aderência ao tratamento, praticamente todos os títulos estão negativos, isto é, dentro dos parâmetros dos indivíduos normais ${ }^{(3,29,37,39)}$. Entretanto, SCOTT et al. ${ }^{(40)}$ observaram que $75 \%$ das crianças celíacas apresentavam títulos de anticorpos IgA negativos após três meses de dieta sem glúten. $\mathrm{O}$ resultado obtido por estes autores difere daqueles dos estudos citados anteriormente que demonstram um declínio mais lento dos títulos do AAG-IgA. Por outro lado, os anticorpos IgG podem persistir elevados por um período mais longo ${ }^{(39)}$.

Títulos altos dos AAG são encontrados em pacientes com enteropatias não-celíaca como, por exemplo, na alergia à proteína do leite de $\operatorname{vaca}^{(3,37,49)}$, na síndrome pósenterite $^{(49)}$, atualmente denominada diarréia persistente, e na doença de $\mathrm{Crohn}^{(49)}$. Títulos positivos destes anticorpos também são relatados em outras doenças não do trato gastrointestinal como, por exemplo, na síndrome de Sjögren ${ }^{(45)}$ e na artrite reumatóide ${ }^{(31)}$.

Entre as diferentes técnicas de determinação dos AAG, o método ELISA (Enzyme-Linked Immunosorbent Assay) é amplamente utilizado na prática, mas a falta de padronização entre os laboratórios e o uso de diferentes métodos de quantificação dos anticorpos dificultam o confronto de resultados. 
Vários estudos mostram que a sensibilidade do ELISA na determinação do AAGIgA varia de $42 \%$ a $100 \%$ e a especificidade de $65 \%$ a $100 \%(3,10,21,29,33,36,37,42,47,49,50,51)$. Em relação ao AAG-IgG a sensibilidade varia de $88 \%$ a $100 \%$ e a especificidade de $52 \%$ a $95 \%(10,21,29,33,36,42,47,50,51)$

Vários fatores são apontados para explicar esta diversidade de resultados em relação à sensibilidade e à especificidade dos AAG; entre eles estão aqueles dependentes de variáveis biológicas do paciente como a idade e susceptibilidade genética, e outros vinculados às diferentes preparações nas fases seqüenciais do processamento do método ELISA.

Alguns estudos demostram um aumento gradual dos títulos dos AAG com a idade nos indivíduos normais, entretanto, nas crianças com doença celíaca ativa os níveis dos anticorpos são muito superiores aos valores encontrados em adultos normais ${ }^{(21,23)}$.

De um modo global, há um consenso entre os autores que o AAG-IgA é mais específico para a doença celíaca e o da classe IgG mostra uma maior sensibilidade.

Vale lembrar que naqueles indivíduos sem títulos detectáveis do AAG-IgA, nos quais há suspeita de doença celíaca, é importante a dosagem da concentração sérica da IgA, e na sua ausência a realização da determinação do AAG-IgG.

A presença dos AAG em outras condições patológicas e mesmo em indivíduos normais sugere que estes anticorpos provavelmente não estejam envolvidos na patogênese da lesão celíaca.

Entretanto, a determinação dos AAG é válida e de grande utilidade para selecionar os pacientes para a biopsia intestinal, nos quais se suspeita a presença de doença celíaca, assim como no seguimento dos pacientes celíacos em relação a adesão à dieta sem glúten.

\section{ANTICORPOS ANTI-RETICULINA}

Os anticorpos anti-reticulina (AAR) começaram a ser investigados na doença celíaca no início dos anos $70^{(1)}$. A atividade anti-reticulina embora ainda não bem definida, representa provavelmente a formação de anticorpos contra componentes do tecido conjuntivo.

Estes anticorpos são detectados por imunofluorescência indireta, usando o fígado e o rim de rato como substrato e podem ser tanto das classe IgA ou IgG.

A reticulina não é uma entidade única, mas composta de colágeno, fibronectina e pelo menos uma glicoproteína não-colagenosa adicional. Demonstra-se que os AAR não reagem com o colágeno tipo III, componentes da reticulina não-colagenosa ou fibronectina; parecem ser específicos a outros componentes do tecido conjuntivo ${ }^{(48)}$.

Os resultados de ensaios com os AAR apresentam uma baixa sensibilidade, mas alta especificidade, quando comparados com os testes que avaliam os $\mathrm{AAG}^{(25,49)}$ embora alguns estudos mostrem sensibilidade de $97 \%$ a $100 \%$ e especificidade de $98 \%$ a $100 \%$ do anticorpo anti-reticulina (tipo R1) da classe $\operatorname{IgA}^{(19,27)}$. Os AAR-IgG apresentam um valor diagnóstico limitado para a doença celíaca ${ }^{(41)}$.

Os AAR também são detectados na doença de Crohn e ocasionalmente em outras doenças gastrointestinais ${ }^{(49)}$.

Embora a significância destes anticorpos seja incerta, MAKI et al. ${ }^{(27)}$ constataram a sua associação com a doença celíaca ativa e o seu desaparecimento da circulação, na maioria dos casos, dentro de um ano após a dietoterapia.
Alguns autores são de opinião que os AAR-IgA são de particular valor na triagem da doença celíaca e que o uso combinado dos AAG e AAR permitiria o diagnóstico da doença celíaca ativa em crianças em mais de $95 \%$ dos $\operatorname{casos}^{(19,27)}$.

\section{ANTICORPOS ANTIENDOMÍSIO}

Em 1984, CHORZELSKY et al. ${ }^{(13)}$ demonstraram no soro de pacientes com doença celíaca ou dermatite herpetiforme a presença dos anticorpos antiendomísio (AAE). Estes anticorpos são principalmente da classe IgA e reagem contra a substância que envolve as miofibrilas da musculatura lisa (endomísio), a qual pode corresponder a uma estrutura semelhante à reticulina ou a um componente da superfície das miofibrilas.

Os AAE foram inicialmente detectados, por imunofluorescência indireta, nos cortes de tecido congelado do esôfago de macaco. Em razão das dificuldades em se obter espécimes daquele tecido, estudos atuais mostram que o cordão umbilical humano possui qualidades semelhantes àquelas do esôfago de macaco e recomenda-se o seu uso como substrato para a determinação do $\mathrm{AAE}^{(52)}$.

Estes auto-anticorpos ou os antígenos reconhecidos por ele estariam envolvidos diretamente na patogênese da doença celíaca ${ }^{(34)}$.

Na prática, a identificação dos AAE é trabalhosa e de custo relativamente elevado, o que limita o seu uso nos programas de triagem em larga escala. O teste apresenta limites inerentes a de qualquer teste cujo resultado depende do escore subjetivo do examinador. A determinação dos AAE pode também ser influenciada pela presença simultânea dos anticorpos contra músculo liso ${ }^{(24)}$.

Como os AAE são normalmente da classe IgA, alguns testes falso-negativos poderiam 
refletir a deficiência seletiva de IgA. Nestes casos, a dosagem da IgA sérica facilitaria a interpretação do teste negativo e, por outro lado, existe a possibilidade de detecção dos $\mathrm{AAE}$ da classe $\operatorname{IgG}^{(22,34)}$.

A determinação dos AAE é um dos testes mais específicos no auxílio do diagnóstico da doença celíaca e na monitorização dos pacientes em relação à adesão à dieta sem glúten.

A sensibilidade do AAE em pacientes celíacos não tratados varia de $90 \%$ a $100 \%$ e a especificidade de $97 \%$ a $100 \%{ }^{(12,19,38)}$. Estudos mostram resultados falso-positivos em um paciente que apresentava alergia à proteína do leite de vaca e em outro portador de Giardia lamblia ${ }^{(9,12)}$.

BURGIN-WOLFF et al. ${ }^{(9)}$ analisando o comportamento dos AAE em 340 crianças celíacas não tratadas, com idades que variavam de 4 meses a 18 anos, observaram que a sensibilidade destes anticorpos é menor nas crianças com idade inferior a 2 anos.

Naqueles pacientes que seguem rigorosamente a dieta sem glúten, os títulos dos AAE diminuem com o tempo e freqüentemente não são detectados após 6 a 12 meses da retirada do glúten da dieta. Por outro lado, nas crianças com doença celíaca tratada, títulos altos de AAE aparecem mais rapidamente na resposta a prova do desafio com glúten do que os títulos dos $\mathrm{AAG}$ e $\mathrm{AAR}^{(41)}$.

$\mathrm{Na}$ forma latente da doença celíaca, os títulos dos AAE podem ser marcadores úteis da progressão das alterações morfológicas da mucosa jejunal que ocorre nesta forma de apresentação da doença. Estes anticorpos também estão presentes no soro de pacientes portadores de doença celíaca potencial ${ }^{(35,46)}$.

A determinação do AAE é particularmente útil para a triagem da doença celíaca entre os familiares de primeiro grau dos pacientes celíacos; naqueles casos duvidosos como, por exemplo, que apresentam títulos de anticorpos antigliadina IgA normal e IgG alto e nas formas atípicas da doença celíaca. A avaliação dos AAE também é importante no rastreamento da doença celíaca entre os pacientes portadores de enfermidades, que mais freqüentemente podem estar associadas à doença.

\section{ANTICORPOS ANTITRANSGLUTAMI- NASE TECIDUAL}

A transglutaminase tecidual (tTG) está largamente distribuída nos órgãos humanos. Esta enzima é secretada por vários tipos de células e embora seja primariamente uma enzima do compartimento intracelular, pode ser secretada pelas células e se acumular no extracelular. A sua função fisiológica ainda não é bem definida, mas há evidências de que a tTG pode ter um papel importante na formação e estabilização da matriz extracelular. Esta enzima pertence à família das enzimas dependentes de cálcio e catalisam a ligação cruzada entre os resíduos de glutamina e lisina em substratos protéicos.

Recentemente, em 1997, DIETERICH et al. ${ }^{(15)}$ identificaram a tTG como sendo o autoantígeno da doença celíaca reconhecido pelo anticorpo antiendomísio.

A gliadina, a fração deletéria do glúten, é rica em resíduos de glutamina e possui poucos resíduos de lisina; entretanto, é um excelente substrato para a tTG. Demonstra-se, por outro lado, que a expressão da tTG está aumentada na doença celíaca ativa ${ }^{(7)}$.

Em seu estudo, DIETERICH et al. ${ }^{(15)}$ propõem que a tTG extracelular catalisa a ligação cruzada da gliadina, resultando na formação de complexos gliadina-gliadina ou gliadina- tTG, que agem como neoepítopes antigênicos, que poderiam iniciar uma resposta imune nos indivíduos geneticamente susceptíveis. MOLBERG et al. ${ }^{(30)}$ sugerem que a produção destes epítopes, por modificação enzimática, poderia ser um novo mecanismo relevante para a quebra da tolerância oral e início da doença auto-imune.

DIETERICH et al. ${ }^{(15)}$ também introduziram o método ELISA para a determinação dos auto-anticorpos da classe IgA contra a tTG, o mais recente auto-antígeno identificado da doença celíaca. Ao lado de SULKANEN et al. ${ }^{(43)}$ concluíram que a detecção destes anticorpos, utilizando método ELISA, é apropriada na triagem para a doença celíaca e no seguimento dos pacientes em relação à adesão à dieta isenta de glúten. Os estudos mostraram uma sensibilidade de $95 \%$ a $98 \%$ e especificidade de $94 \%$ a $95 \%$ para estes anticorpos, e redução dos seus títulos após a introdução da dieta isenta de glúten. Observou-se também excelente correlação entre os auto-anticorpos anti-tTG-IgA e os AAE, determinados pela técnica ELISA e pela imunofluorescência, respectivamente ${ }^{(16,43)}$.

Demonstra-se que a concordância entre as determinações dos anticorpos antiendomísio e anti-tTG é de $100 \%$ para a doença celíaca não tratada, de $94 \%$ para os controles e de $76 \%$ para a doença celíaca tratada ${ }^{(2)}$.

Em razão da alta sensibilidade e especificidade dos anticorpos anti-tTG e da simplicidade e possibilidade de análise de um grande número de amostras do método ELISA, a avaliação destes anticorpos na prática clínica poderá ser de grande utilidade no auxílio ao diagnóstico da doença celíaca. Além do mais, permitirá o rastreamento da doença celíaca nos indivíduos de alto risco e a determinação correta da sua prevalência na população geral.

Em resumo, os ensaios de dosagem dos anticorpos séricos são comumente usados e de grande utilidade no início da investigação da doença celíaca e o encontro de títulos positivos dos anticorpos indicam a realização da biopsia intestinal. Atualmente, a deter- 
minação dos anticorpos circulantes antigliadina e antiendomísio é largamente usada para o rastreamento da doença celíaca, assim como na monitorização dos pacientes em relação à aderência ao tratamento.
Em face ao que foi exposto, pode-se concluir que a presença dos anticorpos contra o antígeno externo (gliadina), assim como dos auto-anticorpos anti-reticulina, antiendomísio e antitransglutaminase tecidual, embora úteis como marcadores sorológicos da doença celíaca, não atingem acurácia elevada para serem considerados patognomônicos da doença e, deste modo, substituir a biopsia intestinal para o seu diagnóstico.

Romaldini CC, Barbieri D. Celiac disease serum antibodies. Arq Gastroenterol, São Paulo, 36(4):259-265, 1999.

ABSTRACT - Accurate diagnosis of celiac disease is important because patients are advised to adhere to a strict gluten-free diet for life. This management is critical to avoid disease complications such as malignancies. In this review the new terminology for the disease clinical features (active, silent, latent and potential celiac disease) and the disease association with other conditions are commented. The value and efficacy of the assessment of serum antigliadin antibodies and of antireticulin, antiendomysial and tissue transglutaminase autoantibodies in the diagnosis and follow-up of the celiac disease are particularly evaluated.

HEADINGS - Celiac disease. Serological markers. Serum antibodies. Gliadin. Reticulin. Endomysium. Transglutaminase, tissue

\section{REFERÊNCIAS BIBLIOGRÁFICAS}

1. Alp MH, Wright R. Autoantibodies to reticulin in patients with idiopathic steatorrhoea, coeliac disease and Crohn's disease, and their relation to immunoglobulins and dietary antibodies. Lancet, 2:682, 1971 .

2. Arranz MC, Ayesta A, Riñon M, Maruri N, Vitoria JC, Masdevall MDG, Arreta A. Relationship between antigliadin, antiendomisial and tissue transglutaminase antibodies in coeliac disease. In: International Symposium on Coeliac Disease, 8., Naples, 1999. Abstract book. Naples, 1999. [Abstract P 033 p. 191].

3. Ascher H, Lanner A, Kristiansson B. A new laboratory kit for anti-gliadin IgA at diagnosis and follow-up of childhood celiac disease. J Pediatr Gastroenterol Nutr, 10:443, 1990.

4. Bao F, Yu L, Babu S, Wang T, Park Y, Uhlhorn C, Hoffenberg EJ, Erlich HA. One third of HLA DQ2 homozygous patients with type 1 diabetes express celiac disease associated transglutaminase autoantibodies. Diabetes, 48:A208, 1999. Suppl. [Apresentado a 59. Scientific Sessions of American Diabetes Association, San Diego, 1999].

5. Barbieri D. Doença celíaca. In: Barbieri D, Koda YKL, ed. Doenças gastroenterológicas em pediatria. São Paulo, Atheneu, 1996. p.176-88.

6. Berger E. Zur allergisches pathogenese der coeliakie. Int Ver Pediatr, 67:1-55, 1958 apud Troncone R, Ferguson A. Anti-gliadin antibodies. J Pediatr Gastroenterol Nutr, 12:150, 1991.
7. Bruce SE, Bjarnason I, Peters TJ. Human jejunal transglutaminase: demonstration of activity, enzyme kinects and substrate specificity with special relation to gliadin and coeliac disease. Clin Sci, 68:573, 1985.

8. Burgin-Wolff A, Bertele RM, Berger R, Gaze H, Harms HK, Just M, Khanna S, Schurmann K, Signer E, Tomovic D. A reliable screening test for childhood celiac disease: fluorescent immunosorbent test for gliadin antibodies. J Pediatr, 102:655, 1983.

9. Burgin-Wolff A, Gaze H, Hadziselimovic F, Huber H, Lentze MJ, Nusslé D, Reymond-Berthet C. Antigliadin and antiendomysium antibody determination for coeliac disease. Arch Dis Child, 66:941, 1991 .

10. Calabuig M, Torregosa R, Polo P, Tuset L, Tomás C, Alvarez V, Garcia-Vila A, Brines J, Vilar P, Farré C, Varea V. Serological markers and celiac disease: a new diagnostic approach? J Pediatric Gastroenterol Nutr, 10:435, 1990.

11. Cataldo F, Marino V, Bottaro G, Greco P, Ventura A. Celiac disease and seletive immunoglobulin A deficiency. J Pediatr, 131:306, 1997.

12. Chan KN, Phillips AD, Mirakian R, Walker-Smith JA. Endomysial antibody screening in children. J Pediatr Gastroenterol Nutr, 18:316, 1994.

13. Chorzelsky T, Beutner E, Sulej J, Tchorzewska H, Jablonska S, Kumar V. IgA antiendomysium antibody. A new immunological marker of dermatitis and coeliac disease. Br J Dermatol, 111:395, 1984. 
14. Collin P, Salmi J, Haellstroem O, Reunala T, Pasternack A. Autoimmune thyroid disorders and coeliac disease. Eur J Endocrinol, 130:137, 1994.

15. Dieterich W, Ehnis T, Bauer M, Donner P, Volta U, Rieken EO, Schuppan D. Identification of tissue transglutaminase as the autoantigen of celiac disease. Nat Med, 3:797, 1997.

16. Dieterich W, Laag E, Schoopper H, Volta U, Ferguson A, Gillett H, Riecken EO, Schuppan D. Autoantibodies to tissue transglutaminase as predictors of celiac disease. Gastroenterology, 115:1317, 1998.

17. Ferguson A, Arranz E, O’Mahony S. Cinical and pathological spectrum of coeliac disease - active, silent, latent, potential. Gut, 34:150, 1993.

18. Greco L, Troncone R, Vizia B, Poggi V, Mayer M, Grimaldi M. Discriminant analysis for the diagnosis of childhood celiac disease. J Pediatr Gastroenterol Nutr, 6:538, 1987.

19. Hallstrom O. Comparison of IgA class reticulin and endomysium antibodies in coeliac disease and dermatitis herpetiformis. Gut, 30:1225, 1989 .

20. Holmes GKT, Prior P, Lane MR, Pope D, Allan RN. Malignancy in coeliac disease-effect of a gluten free diet. Gut, 30:333, 1989.

21. Kelly J, O'Farrelly C, Rees JPR, Feighery C, Weir DGW. Humoral response to a-gliadin as serological screening test for coeliac disease. Arch Dis Child, 62:469, 1987.

22. Korponay IR, Szabó JB, Kovaés A, Czinner A, Gorácz G, Vámos A, Szabó T. Contribution of IgG-endomisium antibody testing to autoantibody based coeliac disease screening. J Pediatr Gastroenterol Nutr, 24:462, 1997. [Apresentado a Annual Meeting of the European Society of Pediatric Gastroenterology and Nutrition, Thessaloniki, 1997].

23. Kumar V, Jain N, Lerner A, Beutner EH, Chorzelski TP, Lebenthal E. Comparative studies of different gliadin preparations in detecting antigliadin antibodies. J Pediatr Gastroenterol Nutr, 5:730, 1986.

24. Lasagni D, Ferrari R, Lapini M. Unmasking anti-endomysial antibodies in coeliac subjects positive for anti-smooth muscle antibodies. Acta Paediatr, 88:462, 1999.

25. Lazzari R, Volta U, Bianchi FB, Collina A, Pisi E. R1 reticulin antibodies markers of celiac disease in children on a normal diet and on gluten challenge. J Pediatr Gastroenterol Nutr, 3:516, 1984.

26. Logan RFA, Rifkind EA, Turner ID, Ferguson A. Mortality in celiac disease. Gastroenterology, 97:265, 1989.

27. Maki M, Hallstrom O, Vesikari T, Visakorpi JK. Evaluation of a serum IgA-class reticulin antibody test. J Pediatr, 105:901, 1984.

28. Marsh MN. Gluten, major histocompatibility complex, and the small intestine. A molecular and immunobiologic approach to the spectrum of gluten sensitivity (“celiac sprue”). Gastroenterology, 102:303, 1992.

29. Medeiros EHGR. Anticorpo sérico antigliadina no diagnóstico e seguimento da doença celíaca. São Paulo, 1992. [Tese - Doutorado - Escola Paulista de Medicina].

30. Molberg Ø, McAdam SN, Korner R, Quarsten H, Kristiansen C, Madsen L, Fugger L, Scott H, Roepstorff P, Lundin KEA, Sjostrom H, Sollid LM. Tissue transglutaminase selectively modifies gliadinpeptides that are recognized by gut-derived T cells. Nat Med, 4:713, 1998.

31. O'Farrelly C, Marten D, Melcher D. Association between villous atrophy in rheumatoid arthritis and a rheumatoid factor and gliadinspecific IgG. Lancet, 2:819, 1988.

32. Otley C, Hall RP. Dermatitis herpetiformis. Dermatol Clin, 8:759, 1990 .

33. Perticarari S, Not T, Cauci S, Luchesi A, Presani G. ELISA method for quantitative measurement of $\operatorname{IgA}$ and $\mathrm{IgG}$ specific anti-gliadin antibodies. J Pediatr Gastroenterol Nutr, 15:302, 1992.

34. Picarelli A, Maiuri L, Frate A, Greco M, Auricchio S, Londei M. Production of antiendomysial antibodies after in-vitro gliadin challenge of small intestine biopsy samples from patients with coeliac disease. Lancet, 348:1065, 1996.

35. Picarelli A, Maiuri L, Mazzilli MC, Coletta S, Ferrante P, Giovambatista F, Greco M, Torsoli A, Auricchio S. Gluten-sensitive disease with mild enteropathy. Gastroenterology, 111:608, 1996.

36. Rich EJ, Christie DL. Anti-gliadin antibody panel and xylose absorption test in screening for celiac disease. J Pediatr Gastroenterol Nutr, 10:174, 1990.

37. Romaldini C, Barbieri D. Estudo do anticorpo sérico antigliadina da classe imunoglobulina-A na doença celíaca. Arq Gastroenterol, 34:254, 1997.

38. Rossi TM, Kumar V, Lerner A, Heitlinger LA, Tucker N, Fisher J. Relationship of endomysial antibodies to jejunal mucosal pathology: specificity towards both symptomatic and asymptomatic celiacs. J Pediatr Gastroenterol Nutr, 7:858, 1988.

39. Savilahti E, Perkkio M, Kalimo K, Viander M, Vainio E, Reunala T. IgA antigliadin antibodies: a marker of mucosal damage in childhood coeliac disease. Lancet, 2:320, 1983.

40. Scott H, Ek J, Brandtzaeg P. Changes of serum antibody activities to various dietary antigens related to gluten withdrawal or challenge in children with coeliac disease. Int Arch Allergy Appl Immunol, 76:138, 1985.

41. Scott H, Kett K, Halstensen TS, Hvatum M, Rognum TO, Brandtzaeg. The immune system in coeliac disease. In: Marsh M, ed. Coeliac disease. Oxford, Blackwell, 1992. p.239-82. 
42. Stahlberg M.R, Savilahti E, Viander M. Antibodies to gliadin by ELISA as a screening test for childhood celiac disease. J Pediatric Gastroenterol Nutr, 5:726, 1986.

43. Sulkanen S, Halttunen T, Laurila K, Kolho KL, Korponay-Szabó IR, Sarnesto A, Savilahti E, Collin P, Maki M. Tissue transglutaminase autoantibody enzyme-linked immunosorbent assay in detecting celiac disease. Gastroenterology, 115:1322, 1998.

44. Taylor KB, Truelove SC, Thomson DL, Wright R. An immunological study of coeliac disease and idiopathic steatorrhoea. Br Med J, 2:1727, 1961

45. Teppo AM, Maury CPJ. Antibodies to gliadin, gluten and reticulin glycoprotein in rheumatic diseases: elevated levels in Sjogren's syndrome. Clin Exp Immunol, 57:73, 1984.

46. Troncone R, Greco L, Mayer M, Paparp F, Caputo N, Micillo M, Mugione P, Auricchio S. Latent and potential coeliac disease. Acta Paediatr, Suppl 412:10, 1996.

47. Tucker NT, Barghuthy FS, Prihoda TJ, Kumar V, Lerner A, Lebenthal E. Antigliadin antibodies detected by enzyme-linked immunosorbent assay as a marker of childhood celiac disease. J Pediatr, 113:286, 1988.
48. Unsworth DJ, Scott DL, Walton KW. Failure of R1 type antireticulin antibody to react with fibronectin, collagen type III or the non-collagenous reticulin component (NCR). Clin Exp Immunol, 57:609, 1984

49. Unsworth, DJ, Walker-Smith JA, Holborow EJ Gliadin and reticulin antibodies in childhood coeliac disease. Lancet, 1:874, 1983.

50. Volta U, Lenzi M, Cassani F, Lazzari R, Bianchi FB, Pisi E. Gliadin antibodies in coeliac disease. Lancet, 1:1285, 1983.

51. Volta U, Lenzi M, Lazzari R, Cassani F, Collina A, Bianchi FB, Pisi E. Antibodies to gliadin detected by immunofluorescence and a micro-ELISA method: markers of active childhood and adult coeliac disease. Gut, 26:667, 1985.

52. Volta U, Molinaro N, De Franceschi L, Bianchi FB. Human umbilical cord as substrate for IgA antiendomysial antibodies allows large screening for celiac sprue. J Clin Gastroenterol, 23:18, 1996

53. Zubillaga P, Vitoria JC, Arrieta A, Echaniz P, Garcia-Masdevall MD. Down's syndrome and celiac disease. J Pediatr Gastroenterol Nutr, 16: 168, 1993 